\title{
LA UNIVERSIDAD LETRADA. DOCENCIA E INVESTIGACIÓN UNIVERSITARIA EN ESPAÑA
}

\author{
RAQUEL MARTÍNEZ CHICÓN \\ ANTONIA OLMOS ALCARAZ \\ Universidad de Granada
}

RESUMEN: El presente texto realiza una comparación metafórica entre La Cuidad Letrada descrita por Ángel Rama y la realidad de la Universidad española en la actualidad con un trasfondo de igual reivindicación: «la democratización de las funciones intelectuales». Para ello, recurrimos a una metodología auto-etnográfica y a la narración de nuestro acontecer dentro de la academia. Prestamos especial atención a las crecientes lógicas mercantilistas de la institución y a «los nuevos letrados" -agencias de control de la calidad del conocimiento - y reflexionamos sobre algunas categorías sociales como las de edad y género en tanto constructoras de diferencia y mantenedoras de estructuras de poder y desigualdad.

PALABRAS CLAVE: Democracia y ética en la Universidad; mercantilización del conocimiento; identidad; relaciones de poder; La Ciudad Letrada.

\section{The Lettered University. University Teaching and Research in Spain}

ABSTRACT: The present paper performs a metaphorical comparison between the Lettered city described by Ángel Rama and the reality of the Spanish University today with the same claim: "the democratization of intellectual functions". For this we will resort to an auto-ethnographic methodology, and the narration of ours experiences inside the Academy. We focus on the increased mercantilization of the institution and «new Lettereds" - agencies of control of knowledge and quality - and reflected on some social categories such as age and gender as builders of difference and maintainer of structures of power and inequality.

KEY WORDS: Democracy and ethics at the University; mercantilization of knowledge; identity; power relations; The Lettered City.

\section{LA PROFESIÓN «ELEGIDA»}

Partiendo de la consideración de que la docencia universitaria, mucho más allá de una ocupación es una «Profesión»(Cortina, 1996, 1997), en todas sus dimensiones y significados, en tanto que es ejercida por un conjunto de profesionales capacitados y formados de manera continua, que presta un servicio especializado y específico a la sociedad desde una institución generada para ello; podríamos afirmar que es una de las actividades sociales más importantes.

A su vez, si el «núcleo ético de toda profesión radica en el servicio que presta a la sociedad para satisfacer alguna necesidad real y no en el prestigio o arraigo de la institución concreta que preste dicho servicio» (Martínez, 2006: 81), al participar directamente y responder no sólo a la formación sino a los procesos 
de transmisión-adquisición de la cultura' ${ }^{1}$, la profesión docente se situaría en el plano de la ética y de la moral de la máxima responsabilidad (Martínez, 2010).

Esta responsabilidad implica, precisamente, que el servicio de formación que se presta a la sociedad debe responder a los requisitos de excelencia por parte de los y las profesionales, pero también de las instituciones.

En lo que atañe al profesorado universitario, implica vigilar de manera constante y consciente las prácticas y evitar cualquiera de los posibles riesgos de corrupción, tal y como la define Martínez $(2006)^{2}$. O mejor dicho, no olvidar jamás y practicar la máxima de que: El/la excelente profesor/a universitario/a es aquella persona que es: excelente docente, excelente investigador/a y excelente colega. Pero también, añadiríamos, quien vigila y responde a su deber ético de servicio a la sociedad luchando, de manera comprometida, por la justicia social.

En este mismo sentido, y en lo que atañe a las instituciones, la enseñanza, y en concreto la enseñanza universitaria, alcanzará la excelencia en tanto que sean sus profesionales quienes la alcancen (Zabalza, 2003). Pero esto implica además una base de partida - y una crítica y reivindicación en caso de que esa base se vea socavada, como sucede en la actualidad en el contexto español que sigue propiciando «el orden jerárquico de la ciudad letrada» ${ }^{3}$ - de acceso a toda la enseñanza, en condiciones de igualdad y desde el respeto a la democracia y a la ciudadanía en todas sus dimensiones conceptuales.

Y también, y no menos importante, del acceso al ejercicio de su profesión y a la posibilidad de identificación, realización y reconocimiento profesional en estos mismos términos.

En este sentido, desde hace tiempo en la Universidad española, se vienen produciendo cambios legislativos que pretenden acabar con las dinámicas de clientelismo y endogamia de la que ha sido sospechosa y acusada durante mucho tiempo. Esto se está llevado a cabo mediante la gestión y el control de lo que se entiende como «criterios de calidad» regidos y examinados a través de

1 Entendemos por transmisión-adquisición de cultura un tipo de proceso más global que los que se desarrollan en las instituciones educativas, que refiere también el contenido que se transmite - la cultura, en términos antropológicos- Lo entendemos además de manera holista, en tanto que ha de ser visto siempre en relación a otros procesos (GARCía Castaño y Pulido Moyano, 1994).

2 Corrupción en tanto que «descuido de la formación permanente; descuido de los aspectos didácticos; descuido de la investigación; improvisación y falta de preparación de las clases; tratamiento del alumnado en términos de amiguetes. $\mathrm{O}$, en el otro extremo, falta de control y de interés por el alumnado, o tratamiento en desigualad de oportunidades; falta de retroalimentación y/o desidia en las correcciones y en la atención tutorial; impuntualidad y/o absentismo; utilización de las lecciones para hacer proselitismo ideológico (político, filosófico o religioso); etc.» (Henry, 1995; Díaz, 2003; MarTínez, 2006).

3 «Hasta el positivismo, incluido, la Universidad fue el centro formativo del pensamiento y las letras y las disciplinas universitarias, por modernizadas que fueran, propiciaban el orden jerárquico de la ciudad letrada, preparaban para las funciones del poder centralizado» (Rama, 1998, 119). 
agencias y empresas tanto públicas como privadas que se supone que, por ser externas a la institución universitaria, velan por la imparcialidad, objetividad, calidad y excelencia en la docencia e investigación. Lo que en realidad no deja de ser un espejismo, o en palabras de Rama «el sueño de un orden a través del sueño de otro orden», que continúa perpetuando relaciones de poder:

El sueño de un orden servía para perpetuar el poder y para conservar la estructura socio-económica y cultural que ese poder garantizaba. Y además se imponía a cualquier discurso opositor de ese poder, obligándolo a transitar, previamente, por el sueño de otro orden (Rama, 1998: 23).

Esta es la profesión que hemos elegido, esta es la profesión para la que nos hemos preparado y para la que nos seguimos formando. Esta es nuestra identidad profesional y nuestra ocupación (lo que somos y lo que hacemos). Y en este espacio, a través de una aproximación auto-etnográfica, queremos poner de manifiesto algunas de las experiencias vividas que han caracterizado nuestro devenir por la institución en los últimos años. Haremos mención expresa a los obstáculos sorteados en el camino ${ }^{4}$, derivados de relaciones hegemónicas ${ }^{5}$ externas y de dinámicas internas de poder basados, entre otros en: grupos de adscripción (a veces voluntaria y a veces forzada), referencias formativas y profesionales de mayor o menor prestigio, edad y sexo-género; y que han dificultado, desde fuera y desde dentro de la propia universidad, esa base de partida de la que hablábamos.

\section{UNA NOTA METODOLÓGICA: DE LA BIOGRAFÍA A LA AUTO-ETNOGRAFÍA.}

El método biográfico ha sido usado en ciencias sociales tradicionalmente para dar voz a quienes estaban situados en posiciones subalternas (Davis y Pradilla, 2003). Aún así —o quizá por eso mismo— Ferrarotti afirma que «es posible leer una sociedad a través de una biografía» (en Iniesta y Feixa, 2006: 11). Nosotras hacemos nuestras estas afirmaciones añadiendo interpretación, y afirmamos que es posible conocer una institución (léase la universidad) a través

4 Muchos de ellos relacionados con las salidas profesionales que estudia Julia Evvets (2003).

5 Un medio habitual de lograr la dominación es que los grupos hegemónicos consigan establecer un férreo control sobre los profesores y las escuelas, de modo que les sirvan para el propósito de difundir una ideología que justifique sus pretensiones de dominación. Algunos profesores (NAVArRo, Torres y Garzón, 2011) han denunciado que en nuestros días los grupos sociales que controlan el poder económico tratan de controlar también la escuela y la enseñanza; prueba de ello sería la progresiva mercantilización de la enseñanza, que se muestra, entre otras cosas, en el hecho de que se ha ido sustituyendo el lenguaje ético-político (que habla de la educación en términos de un derecho básico, de igualdad de oportunidades, de promover la libertad del alumno, de sentido crítico, de creatividad, etc.,) por un lenguaje tecnocrático y economicista que prefiere hablar de "calidad», de "competitividad», de «clientes», de empleabilidad, etc.) (MARTínez, 2006). 
de una auto-etnografía. El elemento de subalternidad vendría dado en este caso por nuestra adscripción y categorización como neófitas dentro del cuerpo docente universitario, a pesar de contar con más de 10 años de experiencia en el mismo desde que iniciamos nuestra trayectoria como investigadoras. Y la valoración positiva del enfoque interpretativo nos distancia de la pretensión de objetividad, dominante en los discursos científicos decimonónicos. Es por ello que presentamos un trabajo auto-etnográfico, y no auto-biográfico que esté bajo el encuadre de la epistemología positivista (Blanco, 2012a), reivindicando con ello la descolonización de las ciencias sociales (De Sousa Santos, 2010; Grosfoguel, 2011).

La auto-etnografía se plantea principalmente como un método de investigación para el estudio de grupos sociales, instituciones y/o espacios de pertenencia del propio investigador/a (Bochner y Ellis, 2003). Es una forma de generación de conocimiento que conecta lo personal con lo cultural, lo social y lo político $\left(\right.$ Ellis, 2008) ${ }^{6}$. El resultado es un texto donde el/la investigador/a relata su propia experiencia, al tiempo que deja emerger las características que definen el contexto donde se inserta dicha experiencia.

Una última particularidad de la aproximación auto-etnográfica que destacamos en este momento tiene que ver con el género del producto final, dado que posee «una estructura narrativa (que incluye una trama o el argumento del relato)»(Blanco, 2012b: 57). A este respecto, diversos autores afirman que, si bien, la auto-etnografía siempre se escribe en primera persona, el texto resultante puede aparecer en una amplia gama de formatos: relatos de ficción, dramas, textos performance, novelas, ensayos, aforismos, comedia y sátira, presentaciones audiovisuales, alegorías, conversaciones, géneros mixtos, etc. (Richarson, 2003 citado en Blanco, 2012b).

Esta es la forma elegida para este trabajo, y este es el trabajo elegido: un diálogo con la obra de Ángel Rama que permita establecer comparaciones metafóricas entre la ciudad letrada y lo que hemos venido a llamar la universidad letrada. Esta conversación no deja de ser un recurso narrativo y una estrategia literaria para la reconstrucción de experiencias y observaciones de una Universidad que entendemos «ordenada, letrada, escrituraria y modernizada» e inmersa en un proceso de pérdida de valores y criterios democráticos.

\section{UNA NOTA AUTO-ETNOGRÁFICA}

Quienes suscribimos este artículo somos dos Profesoras e Investigadoras que nos hemos formado y hemos tenido experiencias profesionales dentro y fuera de la universidad. Ambas teníamos en el momento de la redacción de este artículo un contrato laboral temporal a tiempo completo de docencia e investigación denominado «Profesoras Ayudantes Doctoras», y poseíamos en

\footnotetext{
6 Traducción propia.
} 
el momento de firma de dicho contrato la acreditación para una figura laboral superior y estable ${ }^{7}$.

En un caso pasaron cinco años desde la lectura de la tesis hasta la obtención de la plaza, habiendo centrado la actividad profesional en el ámbito universitario en diferentes universidades nacionales y extranjeras de prestigio. En el otro caso, transcurrieron ocho años desde la lectura de la tesis hasta la obtención de la plaza, habiendo compaginado la actividad profesional en un puesto de responsabilidad en otra administración pública con la docencia asociada en una universidad nacional.

En las dos situaciones, la trayectoria y la experiencia laboral no solo nos ha acreditado como profesionales, sino que ha contribuido como aval para nuestra posición actual dentro de la universidad, permitiendo además la formación continua y el compromiso de excelencia ${ }^{8}$ como docentes e investigadoras en un nivel de la enseñanza denominado «superior», en el que:

[...] el profesor universitario está llamado a completar la formación de los alumnos como profesionales de alto nivel, pero sin descuidar la vertiente de su formación como personas y como ciudadanos que muy probablemente serán los dirigentes de la sociedad en el futuro [...] como investigador se espera de él que amplíe cuanto pueda conocimientos metodológicamente contrastados y controlados (Hortal, 2000: 70).

Es cierto que la legislación, los requisitos y posibilidades de acceso y promoción universitaria en España han cambiado y se han endurecido en los últimos años con los argumentos de la crisis económica y de la adecuación a los «estándares de calidad internacional». Pero no menos cierto es que las nuevas políticas laborales están mermando y eliminando muchos derechos que ya habían sido conquistados décadas atrás y precarizando cada vez más el trabajo y el empleo en todos los sectores, entre ellos, el académico. Así, la situación de desigualdad, elitismo y jerarquización existente entre el propio profesorado está acrecentándose a niveles sin precedentes en términos de estabilidad/temporalidad, retribución económica y derechos reconocidos; tal y como sucedía entre las clases escribientes y burócratas y el común de la sociedad en la realidad que retrata Rama en su obra:

Fue evidente que la ciudad letrada remedó la majestad del Poder, aunque también puede decirse que éste erigió las operaciones letradas inspirado sus principios de concentración, elitismo, jerarquización. Por encima de todo, inspiró la distancia respecto al común de la sociedad. Fue la distancia entre

\footnotetext{
$7 \quad$ Esta es otra de las paradojas de la institución universitaria que responde claramente a intereses económicos y mercantilistas. Convocar plazas laborales de menor categoría y remuneración y agotar los años de contrato antes de la promoción a figuras de mayor estabilidad, aunque se cuente con la acreditación para optar a un nuevo concurso.

8 «Aquí encontramos, a mi modo de ver, una primera clave de la ética del profesor universitario que vamos a expresar en forma de imperativo: reparte su dedicación profesional de un modo equitativo entre la docencia y la investigación, procurando adoptar el ethos de excelencia en ambas actividades» (MARTínez, 2006: 254).
} 
la letra rígida y la fluida palabra hablada, que hizo de la ciudad letrada, una ciudad escrituraria, reservada a una estricta minoría (Rama, 1998: 43).

No debemos perder de vista que el profesorado universitario no es ajeno al sistema sociopolítico y económico en el que se enmarca, y que existen unas dinámicas propias, intrínsecas, pero no exclusivas de la institución universitaria, que determinan las relaciones de poder. Existen también dinámicas que influyen en la configuración de la propia profesión y que, basadas en procesos de construcción identitaria relacionados con la edad, el sexo-género, la etnicidad y los orígenes y vinculaciones formativas previas, en ocasiones determinan dichas relaciones de poder incluso más que la propia trayectoria personal/profesional. Estos marcadores son algunos de los pilares sobre los que se asientan las jerarquías dentro de la universidad y permiten la «colonización del conocimiento» (Grosfoguel, 2011).

De igual manera que Rama (1998) considera que la escritura y la lectura quedó consagrada al grupo letrado, y fue exclusivo su acceso a unos pocos que eran quienes instauraban, mantenían y reproducían el poder, en la actualidad, la posibilidad de aportar, tanto en términos de participación en foros científicos como de publicación de resultados, hace de la Universidad letrada una Universidad escrituraria. Sólo unos pocos, los que ya forman parte de esa estricta minoría, los reconocidos para elaborar unas «leyes» y unos «códigos» son a su vez, quienes mantienen el acceso restringido.

¿Podría esto ayudar a explicar la «autopercepción» de la gran mayoría del profesorado contratado sin vinculación permanente de ser tratados, ahora sí de manera permanente, por otra gran mayoría de «colegas» (a veces hasta con menos méritos académicos) como: «tutelados», "pupilos», siempre "otros» externos al grupo y «eternos aprendices»? En nuestro caso, y en otros muchos casos consultados, así lo consideramos.

4. La «Universidad Letrada»: Relaciones DE PODER Y MERCANTILIZACión DEL CONOCIMIENTO EN ESPAÑA.

En ocasiones puede ser curioso recordar nuestros inicios en la universidad. Acceder a una beca de formación de profesorado universitario y/o una beca de investigación, cuando aún no teníamos muy claro a qué íbamos a dedicarnos en un futuro, fue clave en los nuestros. Pero la curiosidad, obviamente, no reside en el qué nos permitió iniciar nuestra carrera profesional dentro de la universidad, sino en el cómo fueron los primeros años de docentes. Hay varios elementos que queremos destacar en este sentido, y que consideramos claves en la formación de nuestras identidades y roles profesionales.

En primer lugar, es imperativo reflexionar sobre cómo se producen las identidades. No es necesario detenernos en discutir sobre identidad (en singular) o identidades (en plural). Tampoco lo es discutir sobre herencia o aprendizaje. De este modo, entendemos las identidades como algo no sustantivo, ni único, ni esencial: 
[...] cabe asumir que la identidad cultural no es algo sustantivo y permanente. Actualmente se tiende a pensar que la identidad es un proceso. Es decir, frente a concepciones esencialistas prevalecen hoy día visiones mucho más flexibles, que dan cabida no sólo al cambio social, sino también a una multiplicidad de formas inherentes en el mismo proceso de identificación (García García, 1998: 7).

Es más bien una sucesión de procesos, siempre en construcción y redefinición. Se trata de algo transitorio que se modifica en función de los contextos espacio-temporales, con lo que se evidencia muy acertado hablar de «movimiento hacia una identidad perpetuamente por fijar» (Bauman, 2006: 47). Las identidades «nunca son singulares, sino construidas de múltiples maneras a través de discursos, prácticas, posiciones diferentes, a menudo cruzadas y antagónicas» (Hall, 2003: 17).

\subsection{Relaciones de Poder y Edad.}

Son diversos los factores que influyen en el acontecer de los anteriormente mencionados procesos identitarios. La edad es uno de ellos. Quizá uno de los más importantes, aunque es cierto que la centralidad del mismo no es la misma en todas las sociedades e instituciones. La academia parece ser una en donde la edad —o mejor dicho, la apariencia de la edad — sí que importa, y mucho.

Funciona a veces como categoría discriminante en el establecimiento del lugar que ocupa la persona o donde se la ubica. La referencia a la edad permite situar al individuo en el desarrollo de su existencia particular. Pero no se trata de un marcador claramente visible, a no ser que todos/as llevásemos nuestro documento de identidad a la vista. Es por ello que, en tanto que categoría social, para funcionar como criterio de clasificación, producción de orden y distribución de poder (Bourdieu, 2002), recurre a toda una serie de discursos vinculados estrechamente a contextos sociales, históricos, culturales o relacionales (Davila, 2004) que la significan. Ante esto nos planteamos una pregunta: ¿Cuándo se adquiere el estatus de adultez en la academia?, que nos sugiere nuevos interrogantes:

1. Se es adulto... ¿cuándo se deja de ser estudiante?

2. ... ¿cuando se consigue un título de doctor/a?

3. ... ¿cuándo se obtiene una acreditación de Profesor Ayudante? o más bien... ¿cuándo se obtiene una plaza de Profesor Ayudante Doctor?

4. O quizá... ¿cuándo se obtiene una acreditación de Profesor Contratado Doctor? o ... ¿Cuándo se consigue la plaza de Contratado Doctor?,

5. ...

Podemos seguir rellenando líneas hasta llegar a la obtención de la plaza de Catedrático/a, pero es posible que la respuesta no tenga que ver sólo con la acumulación de títulos, sino que operen otras lógicas de jerarquización 
dentro de la universidad (García Castaño, 1989) que estén haciendo posible la categorización (puntual) de sempiterno aprendiz.

Entre estas lógicas, además de la edad (o percepción de juventud), juegan un papel fundamental el sexo-género, la adscripción profesional a un determinado grupo de investigación y/o disciplinas, la procedencia étnico-nacional y la mercantilización y la «re-colonización del conocimiento» por parte de agencias y entidades privadas salvaguardas de la «calidad» docente e investigadora.

Entre estas agencias, en España, centra toda la atención la Agencia Nacional de Evaluación de la Calidad y Acreditación (ANECA) ${ }^{9}$. Ella es quien tiene potestad de «acreditar o desacreditar» en función de determinados ítems, que - aunque son públicos- son lo suficientemente ambiguos y abiertos para ser interpretados dentro de la "discrecionalidad» sin poder ser considerados legalmente como «arbitrarios». Esta cuestión permite la creación y reproducción de espacios de absoluta desprotección en caso de que alguna persona o entidad considere no haber sido correctamente evaluada en sus méritos.

Esta situación de incertidumbre, que hace que toda una carrera profesional se encuentre a merced de unos criterios poco claros que permiten mantener los clientelismos contra los que dice luchar, ha permitido la emergencia de empresas privadas especializadas y especialistas que ofertan a nivel de mercado servicios expertos que «traducen» los méritos a evaluar por la ANECA en méritos «efectivamente valiosos» para la ANECA $^{10}$. En otras palabras, no sólo hace falta tener los recursos económicos para poder hacer méritos sino que incluso teniendo esos recursos y esos méritos éstos pueden no llegar a ser valorados o evaluados positivamente según cómo sean interpretados por unos u otros/as «evaluadores/as» seleccionados/as por la Agencia.

Asimismo, estamos asistiendo en los últimos años a un incremento sin precedentes del coste de la matrícula de Congresos, Jornadas, Seminarios, etc. que hay que abonar de manera anticipada si se quiere hacer efectiva la participación académica. No hace mucho tiempo, quienes aportaban conocimiento o experiencia a través de ponencias o comunicaciones previamente seleccionadas por los comités científicos, estaban exentos del abono de cuotas de inscripción por considerar su aportación equivalente en valor al costo de la matrícula. Hoy en día, no se permite hacer aportaciones si no es de manera posterior al pago de cantidades cada vez más elevadas. Por ejemplo, Congresos de 2 o 3 días cuya inscripción, requisito para poder presentar trabajos (y de este modo acreditar

\footnotetext{
9 «La Agencia Nacional de Evaluación de la Calidad y Acreditación (ANECA) es una fundación estatal que tiene como objetivo contribuir a la mejora de la calidad del sistema de educación superior mediante la evaluación, certificación y acreditación de enseñanzas, profesorado e instituciones» (en <http://www.aneca.es/ANECA $>$ ).

10 Depende de cómo se introduzcan los datos y cómo se presenten éstos, un mismo currículum puede ser valorado positiva o negativamente. Y son esas empresas quienes conocen dónde y cómo hay que incluir, depende qué mérito y reconocido por quién, con objeto de ser positivamente valorado tanto para las acreditaciones como para las evaluaciones posteriores de la actividad investigadora (sexenios).
} 
méritos necesarios para justificar «calidad»), superan en ocasiones los 300€, lo que supone el $20 \%$ del sueldo mensual de un profesor/a en el contexto analizado. A esta cantidad hay que sumar (siempre a nivel personal porque la financiación institucional es muy escasa) los gastos de desplazamiento y alojamiento en caso de que la celebración de estas reuniones científicas sea fuera de la localidad de residencia como suele ser habitual, y eso sólo a nivel nacional sin contar con la participación en Congresos Internacionales. En ocasiones, esta situación se traduce en la obligación de «pagar para trabajar» ya que para poder «acreditarse con calidad» se debe cubrir un "mínimo» de eventos científicos de este tipo, que nunca se llega a saber a priori si van a ser considerados o no suficientes ${ }^{11}$. Todo ello hace que nos preguntemos por el verdadero objetivo de este tipo de eventos en el momento actual: ¿generación e intercambio de conocimiento? ¿consecución de la adultez académica? ¿compra-venta de títulos?... preguntas que ya fueron contestadas por Ángel Rama en el contexto de la Ciudad Letrada: «La única vía moderna y efectiva, consistió en vender la capacidad de escribir en un nuevo mercado del trabajo que se abrió entonces, el mercado de la escritura» (Rama, 1998: 94); descripción que vemos cómo hoy sigue siendo válida para definir lo que metafóricamente estamos denominando como «La Universidad Letrada». En esta «Universidad Letrada», «la libertad también ha sido sustituida por la escritura» (Rama, 1998: 55).

Es necesaria la escritura pero es necesaria la libertad. Libertad para el reconocimiento de la profesionalidad docente e investigadora más allá de la edad y para el reconocimiento de la valía y acreditación más allá de criterios positivistas, neoliberales, cambiantes y discrecionales.

Somos conscientes de la dificultad que implican estas reivindicaciones en un contexto complicado en el que:

Los maestros y profesores tienen una función dentro del sistema de la ciencia, del sistema productivo, del sistema educativo, del sistema curricular de ascenso social propio y del de sus estudiantes. Cómo se sitúan en ese complejo entramado estructural es algo que afecta a su función docente no sólo por la vía de las interferencias, sino también de la configuración intrínseca de su ejercicio profesional (Hortal, 2000: 57).

pero no por ello, podemos dejar de continuar con el análisis, en este caso, sobre la importancia de las adscripciones de sexo-género en este «complejo entramado estructural».

\subsection{Relaciones de Poder y Género}

El concepto de género recoge todo aquello que las diferencias culturales hacen del sexo biológico, y aparece como categoría de análisis en los estudios feministas de la década de los ochenta (Stolke, 1992). No es necesario insistir en el carácter de construcción social del mismo, ni en que hace referencia a

11 Lo que sitúa al profesorado universitario en un estado continuo de «autoexplotación». 
las relaciones entre hombres y mujeres, y no a algo que tenga que ver solo con las mujeres. Tampoco es necesario a estas alturas reparar en el carácter performativo del mismo (Butler, 2007). Son muchas las autoras y autores que han afirmado y afirman que es el género la categoría o principio organizativo de la realidad social que más ha determinado y determina las situaciones de exclusión que viven la mitad de la humanidad con respecto a la otra mitad. Este tipo de discursos fueron especialmente relevantes en las primeras feministas, situadas en contextos occidentales y predominantemente de clase media:

[...] el feminismo radical niega el hecho de que la opresión de la mujer emane meramente de las relaciones de clase (y) la sitúa dentro de esenciales e inamovibles antagonismos de intereses entre hombres y mujeres y, por tanto, la reduce a un conjunto de intereses de fundamento biológico (Anthias y Yuval-Davis, 2002: 259).

Si esto fuese así, los intereses de todos los hombres y de todas las mujeres se opondrían entre sí, y todas las mujeres sufrirían algún tipo de exclusión por el hecho de ser mujeres. Es decir, estaríamos hablando de una subordinación universal de la mujer. Este primer análisis feminista (occidental) postulaba una división esencialista entre hombres y mujeres, que a día de hoy resulta reduccionista, como mínimo, en tanto que dicotómico y heteronormativo (Platero, 2010). Por su parte, las feministas marxistas han explicado esta preeminencia de la discriminación de género respecto a otros tipos de discriminación en la subordinación que sufren las mujeres al estar excluidas de la esfera pública de la producción y su consecuente relegación al trabajo reproductivo dentro de casa:

Los trabajos feministas marxistas (...) han reconocido que, como relación social, el género se construye, en parte, a través de las relaciones económicas y de clase, y que, a nivel empírico, la forma de la experiencia de subordinación y de opresión varía dentro de clases diferentes y de distintos contextos económicos (ibídem: 251-252).

Las explicaciones que el estructuralismo ha aportado sobre la subordinación de las mujeres como principio máximo de exclusión se refieren a su asociación con la naturaleza: debido a su «habilidad» para tener hijos. La mujer, al contrario que el hombre, es relacionada con la naturaleza, lo que le proporciona un estatus adscrito, que le viene dado, es decir, poco valioso; el hombre por su parte aparecería asociado al ámbito de la cultura — no al de la naturaleza como la mujer-, lo que le otorga un estatus adquirido, ganado por sus propios méritos y, por lo tanto, más prestigioso (Gefou-Madianou, 1996).

Ambas explicaciones, marxista y estructuralista, han sido ampliamente discutidas, acusando a las primeras de reduccionismo de clase y las segundas de reduccionismo etnocéntrico ${ }^{12}$. Ninguna de las dos, además, atiende a nociones

12 Las explicaciones marxistas solo eran aplicables a sociedades industrializadas y basadas en la clase social como criterio organizativo, y las explicaciones estructuralistas, sólo en sociedades occidentales donde la dicotomía cultura/naturaleza fuese visible. 
de género de carácter performativo (Butler, 2007) y/o a realidades trans (Platero, 2016). Habría que hacer un análisis más exhaustivo del carácter interseccional (Anthías, 2005; Yuval-Davis, 2006; Platero, 2014) de esta categoría (y de otras). Pero baste ahora con reconocer - y reivindicar- la forma interseccional de funcionamiento de las distintas adscripciones sociales, también por supuesto dentro de la Universidad. En este sentido, el análisis de Rama deja en evidencia la lucha de las mujeres por acceder a la escritura y, a través de la letra, al terreno público y político, a la esfera escrituraria.

Por esto resulta tan interesante reflexionar de manera manifiesta sobre la importancia que tiene el género en la articulación de relaciones sociales dentro de determinados ámbitos de exclusividad y hegemonía como la universidad.

En este sentido, ya hace algún tiempo, se ha hablado de la «rebelión de las empollonas»y del «nuevo sexo débil» (Gil Calvo, 1997) para dar cuenta e intentar describir la situación de mujeres y hombres en distintos contextos, entre ellos el académico, en el momento actual. Es cierto que la mujer tuvo una incorporación tardía respecto al hombre en la universidad española, debido principalmente a la concepción desigual de la función que una y otro - se entendía- debían desempeñar en la sociedad (López de la Cruz, 2002). Con ello a día de hoy se puede aún observar esta disparidad, aunque sea mucho menos pronunciada que antaño ${ }^{13}$. Otra cuestión es que los puestos de responsabilidad, de gestión y de dirección, al igual que los tipos de contratos ostentados por unos y otras sean todavía desiguales ${ }^{14}$. A pesar de todo, no podemos negar que el avance, en tanto que mayor presencia y visibilidad, de las mujeres en la academia española ha sido notable en las últimas décadas. $\mathrm{Y}$ volvemos a insistir en la necesidad de adoptar una lectura interseccional del funcionamiento de las categorías sociales, ya que nuestra experiencia nos indica que es imprescindible poner en relación las adscripciones de clase, edad y género.

\section{A MODO DE CONCLUSIÓN}

Corren tiempos convulsos y cada vez más difíciles para los derechos laborales y para los derechos sociales, para las profesiones y para la actividad docente. Y ahora, más que nunca, es responsabilidad del profesorado universitario, cada uno desde su campo y en tanto que docente e investigador, servir desde la excelencia (Hortal, 1994, 2002):

13 Según datos ofrecidos por la Conferencia de Rectores de las Universidades Españolas (CRUE) para 2010, el 36,2\% del Personal Docente e Investigador de las Universidades Públicas españolas presenciales era mujer, frente al 63,8\% de varones.

${ }_{14}$ A modo de ejemplo podemos mencionar cómo en España en el momento actual sólo 4 de las 50 universidades públicas tienen a una mujer como rectora, o que existe un elevadísimo número de cuadráticos (79\% del total) frente a catedráticas (21\%) (Puy, 2015). 
Sin negar que haya posibilidad y aun necesidad de mantener una cierta distancia (nunca somos del todo y exclusivamente lo que hacemos, también somos alguien distinto, como queda patente en la otra expresión complementaria: «tenemos una profesión») entre nuestra identidad y nuestras ocupaciones. Sin negar que hay que ser cautos y no quemarse en empeños imposibles, hay que saber que en principio no es posible ser buenas personas si no se ejerce bien, competente y honestamente, la profesión que se tiene, el profesional que se es (Hortal, 2000: 78).

Desde las Ciencias Sociales y en concreto desde la Antropología, este compromiso social y de excelencia es requisito previo al ejercicio de la profesión. Para ello, y esto es común para todas las disciplinas y como ya apuntábamos, no podemos olvidar —aunque en ocasiones no solo se obvie sino que se transgreda de manera consciente- que, además de ser excelente docente y excelente investigador, es necesario ser excelente colega, por el bien de la institución.

Y queremos concluir con una reflexión, de nuevo, en forma de interrogante: ¿funcionan estas lógicas de clasificación social en otras instituciones y contextos? Y volvemos a contestar de nuevo con palabras de Ángel Rama:

Esquema dilemático que otros, posteriormente, explicarán con igual criticismo del intelectual por las diferencias de clase, pero que habida cuenta de que ésta es ya una posición intelectual (que confiere la certidumbre histórica a un estrato social) y que bajo otras formas (competencias de instituciones) podemos reencontrar el mismo esquema en distintas épocas y situaciones) podemos inscribirlo en la tradicionalmente difícil conjugación de las dos espadas, de los dos poderes del mundo (Rama, 1998: 124).

Como antropólogas, pero también como mujeres profesionales significadas como jóvenes, sabemos que las adscripciones identitarias y los procesos de construcción de la alteridad, y también las críticas y dilemas a los que hace referencia la obra de la Ciudad Letrada, funcionan en todos los ámbitos de nuestras sociedades. Ello no quiere decir que se trate de un universal cultural. Nada más lejos de la realidad, porque como ya sabemos ésta es construida socialmente (Berger y Luckmann, 1967). Se trata de situaciones contextuales, alimentadas y recreadas por elementos y formas de hacer — sociales y culturales - aprendidas. Por lo tanto evitables, contingentes, coyunturales, volátiles... aunque se muestren asentadas de manera casi sacralizada en el momento actual.

La universidad española lleva décadas trabajando duro por superar y abandonar estas lógicas de funcionamiento clientelares y nepóticas. Creemos que muestras de ello son la diversidad social y cultural presente tanto entre alumnado como entre personal docente e investigador; las políticas de becas vigentes hasta una época muy reciente; y los concursos-oposición públicos de acceso a los cuerpos docentes. No obstante, y no podemos finalizar este texto sin hacer mención a este particular, la situación hoy parece apuntar en otra dirección, porque, sin duda, con los tiempos que corren estamos volviendo muchas décadas hacia atrás a pasos agigantados. Vuelve la ciudad letrada de 
Ángel Rama: «Sólo ella es capaz de concebir, como pura especulación, la ciudad ideal, proyectarla antes de su existencia, conservarla más allá de su ejecución material, hacerla pervivir aún en pugna con las modificaciones sensibles que introduce sin cesar el hombre común» (Rama, 1998: 40).

\section{BiBLIOGRAFÍA}

Anthias, F. (2005). "Social stratification and social inequality: models of intersectionality and Identity», en R. Crompton, F. Devine, J. Scott y M. Savage (eds.), Rethinking Class: cultures, identities, lifestyle, London and Basingstoke: Palgrave, London, pp. 24-45.

Anthias, F. y Yuval-Davis, N. (2002). «Raza y género», en E. Terrén (ed.), Razas en conflicto. Perspectivas sociológicas. Barcelona: Anthropos Editorial, pp. 250-262.

Butler, J. (2007). El género en disputa: el feminismo y la subversión de la identidad. Madrid: Paidós Ibérica.

Bauman, Z. (2006). Vida Líquida. Barcelona: Editorial Paidós.

Bourdieu, P. (2002). "La juventud no es más que una palabra», en P. Bourdieu (comp.), Sociología y cultura. México: Grijalbo, pp. 163-173.

Berger, P. y Luckmann, T. (2006) [1967]. La construcción social de la realidad. Buenos Aires: Amorrortu.

Blanco, M. (2012a). «¿Autobiografía o autoetnografía?», en Desacatos, núm 38, pp. 169178.

Blanco, M. (2012b). «Autoetnografía: una forma narrativa de generación de conocimientos», en Andamios, núm 9 (19), pp. 49-74.

Cortina Orts, A. (1997). Ciudadanos del mundo. Hacia una teoría de la ciudadanía. Madrid: Alianza.

Cortina Orts, A., et al. (1996). Corrupción y Ética. Bilbao: Universidad de Deusto.

CRUE. (2010). La universidad española en cifras. Madrid: CRUE.

Davila León, O. (2004). «Adolescencia y juventud: de las nociones a los abordajes», en Última Década, núm 21, pp. 83-104.

Davis, K. \& Pradilla, V. (2003). «Historia, Antropología y Fuentes Orales», en Memoria Rerum, núm 30, pp. 153-160.

De Sousa Santos, B. (2010). Epistemologias del Sur. México: Siglo XXI.

Díaz Gómez, A. (2003). "Ética y Corrupción. Lo público y la democracia», en Convergencia, núm 31, pp.114-141.

Ellis, C. (2008). «Autoethnography. The sage Encyclopedia of Qualitative Research Methods». Artículo en línea disponible en www.sage-ereference.com/research/Article_n29.html, 2 de diciembre de 2012.

Ellis, C. y Bochner, A. (2003). «Autoethnography, Personal Narrative, Reflexivity. Researcher as Subject», en N. Denzin y Y. Lincoln (eds.), Collecting and Interpreting Qualitative Materials. California: Sage, pp. 199-258.

Evetts, J. (2003). «Identidad, diversidad y segmentación profesional: el caso de Ingeniería», en M. Sánchez, J. Sáez y L. Svensson (coords.), Sociología de las profesiones. Pasado, presente y futuro. Murcia: Librero-Editor, pp. 141-154.

García Castaño, F.J. (1989). Transmisión cultural en una institución educativa universitaria. Análisis antropológico de las relaciones docente-discente, Tesis Doctoral, Universidad Complutense de Madrid. Madrid. 
García Castaño, F. J. y Pulido Moyano, R. A. (1994). Antropología de la educación. Madrid: Eudema.

García García, J. L. (1998). Sobre el significado y las consecuencias de la diversidad cultural. Documento presentado en el Curso Diversidad cultural, exclusión social e interculturalismo desarrollado en la Universidad Internacional de Andalucía, Sede Antonio Machado-Baeza. Jaén.

Gefou-Madianou, D. (1996). "Gender and sex», en A. Kuper y J. Kuper (eds.), The Social Science Enciclopedia. Londres: Routledge.

Grosfoguel, R. (2011). «Decolonizing Post-Colonial Studies and Paradigms of PoliticalEconomy: Transmodernity, Decolonial Thinking and Global Coloniality», en Transmodernity: Journal of Peripheral Cultural Production of the Luso-Hispanic World, núm 1 (1), pp. 1-38.

Hall, S. (2003). «Quién necesita identidad?», en S. Hall y P. Gu Gay (eds.), Cuestiones de identidad cultural. Buenos Aires: Amorrortu, pp. 13-99.

Henry, C. (Ed.) (1995). Professional ethics and organisational change in education and health. Londres: Edward Arnold.

Hortal, A. (1994). La ética profesional en el contexto universitario. Lección inaugural del curso académico 1994-1995 de la Universidad Pontificia Comillas. Madrid: Universidad Pontificia Comillas.

Hortal, A. (2000). «Docencia», en A. Cortina y J. Conill (dir.), 10 Palabras clave en ética de las profesiones. Navarra: Editorial Verbo Divino. Navarra, pp. 55-78.

Hortal, A. (2002). Ética general de las profesiones. Bilbao: Desclée de Brouwer.

Iniesta, M. y Feixa, C. (2006). «Historias de vida y Ciencias Sociales. Entrevista a Franco Ferrarotti», en Perifèria. Revista de recerca i formació en antropología, núm 5, pp. $1-14$.

López de la Cruz, L. (2002). «La presencia de la mujer en la universidad española», en Revista Historia de la Educación Latinoamericana, núm 4, pp. 1-9.

Martínez Navarro, E. (2006). «Ética de la profesión: proyecto personal y compromiso de ciudadanía», en Revista Veritas, núm 14, pp. 121-139.

Martínez Navarro, E. (2010). Ética profesional de los profesores. Bilbao: Desclée de Brouwer.

Navarro, V., Torres López, J. y Garzón Espinosa, A. (2011).Hay alternativas. Propuestas para crear empleo y bienestar social en España, Sequitur. ATTAC España. Madrid.

Platero, R. (L.). (2010). «Sobrevivir al Instituto y a la Facultad: voces y vivencias sobre la heteronormatividad, la homofobia y la masculinidad de las chicas», en Revista de Estudios de Juventud, núm. 89, pp. 39-58.

Platero, R. (L.). (2014). «Metáforas y articulaciones para una pedagogía crítica sobre la interseccionalidad», en Quaderns de Psicología, vol. 16, núm. 1, pp. 55-72.

Platero, R. (L.) (2016). «La transfobia también es una lucha feminista», en Viento Sur. Por una izquierda alternativa, núm. 146, pp. 55-61.

Puy, A. Científicas en cifras 2015. Estadísticas e indicadores de la (des)igualdad de género en la formación y profesión científica. Ministerio de Economía, Industria y Competitividad. Madrid. 2015.

Rama, A. (1998). La ciudad letrada. Arca. Montevideo. Madrid.

Richardson, L. (2003). «Writing. A Method of Inquiry», en N. Denzin y Y. Lincoln, (eds.), Collecting and Interpreting Qualitative Materials. California: Sage.

Stolke, V. (1992). «¿Es el sexo para el género como la raza para la etnicidad?», en Mientras Tanto, núm 48, pp. 87-111. 
Yuval-Davis, N. (2006). «Intersectionality and Feminist Politics», en European Journal of Women's Studies, núm 13 (3), pp. 193-209.

Zabalza Beraza, M.A. (2003). Las competencias docentes del profesorado universitario: calidad y desarrollo profesional. Madrid: Narcea.

Universidad de Granada

raquelchicon@ugr.es

Raquel Martínez Chicón

antonia@ugr.es

Antonia Olmos Alcaraz

[Artículo aprobado para publicación en diciembre de 2016] 